\title{
Local Hemostatic Activity of Psidium guajava Leaves in Swiss Webster Mice
}

\author{
Cszahreyloren Vitamia, Angga Saputra
}

Bumi Siliwangi Academy of Pharmacy, Bandung, West Java, Indonesia

\begin{abstract}
Psidium guajava (P. guajava) leaves have been empirically used to stop bleeding. Tannin, one of this plant's secondary metabolites, may contribute to this activity. However, information regarding its pharmacologicy activity was limited. Therefore, this study was performed to evaluate local hemostatic activity of $P$. guajava leaves. This study used Duke method with male Swiss Webster mice as test animals. The animals were grouped into three i.e., negative control (distilled water), positive control (epinephrin), and P. guajava group. Its tail was cut $(2-3 \mathrm{~mm})$ and the bleeding time was calculated. Statistical analysis was performed using Kruskal-Wallis test and continued with Least Significant Different (LSD) test. The mean (SD) of bleeding time for those groups were 246.00 (22.95), 72.40 (5.55), and 88.40 (7.03), respectively. There was a significant difference between the negative control group with the other two groups, but there was not significant difference between the positive control group and the $P$. guajava group. In conclusion, $P$. guajava showed promising local hemostatic activity and can be further developed as potential hemostatic agents.
\end{abstract}

Keywords: Psidium guajava, hemostatic, bleeding time

\section{Introduction}

External bleeding refers to blood coming from an open wound. The hemostatic mechanism of the body is normally sufficient to repair the damage and stop the blood outflow. Hemostatic mechanism involves three major steps; the vascular spasm, the formation of platelet blockage, and blood coagulation. ${ }^{1,2}$

Psidium guajava (P. guajava) leaves have been empirically used as traditional medicine to stop bleeding. Tannin, one of this plant's secondary metabolites, may contri- bute to this activity. It is a complex chemical compound consisting of polyphenols. The highest concentration of tannin can be found in leaves, stems, and roots. It is an astringent which has the ability to form complex compounds with macromolecules, such as protein. This ability can increase the blood clotting process. ${ }^{3,4}$

To date, research on the hemostatic effects of P. guajava leaves was limited. Therefore, this study was aimed to evaluate hemostatic ac-

Corresponding author: Cszahreyloren Vitamia. Bumi Siliwangi Academy of Pharmacy (Akademi Farmasi Bumi Siliwangi), Bandung, West Java, Indonesia. Email: cszahreyloern@gmail.com

Received: 20 August 2017. Revised: 26 September 2017. Published: 1 December 2017 
tivity of $P$. guajava leaves in Swiss Webster mice.

\section{Methods}

Study design

This was an experimental study with three groups, i.e., negative control (distilled water), positive control (epinephrine-water 1:1000) and treatment group ( $P$. guajava leaves juice). Ten $\mathrm{ml} P$. guajava leaves juice was made by grinding the leaves. Fifteen Swiss Webster mice were used as test animals. The animals were selected using simple random sampling. Male Swiss Webster mice were selected since it is easier to maintain and relatively inexpensive. Parameters observed in this study were the time from the start of the bleeding to the absence of blood drips, which implying hemostatic velocity. ${ }^{5}$

Duke method, in which minor injury was performed on the tail of mice, was selected. The blood was then absorbed by filter paper. The bleeding time was recorded and the mean time was calculated. This method is used for primary hemostatic testing or small bleeding.

\section{Data analysis}

The data obtained from the study were grouped and analyzed statistically with the data normality, homogeneity, and comparability test;

1. Normality analysis

Normality test was perfromed to evaluate the data distribution using Shapiro-Wilk test.

2. Analysis of homogeneity

Data homogeneity analysis was done by variance test (Levene's test of variance). The variance test shows that the data was homogeneous with $\mathrm{P}>0.05$.

3. Comparability analysis

Kruskal-Wallis test was employed to analyze inter-group comparative data, continued with Least Significant Different (LSD) test.

\section{Results and Discussion}

The mean (SD) of bleeding time for control negative, control positive, and treatment groups were 246.00 (22.95), 72.40 (5.55), and 88.40 (7.03), respectively. This data suggests that $P$. guajava shorten the bleeding

Table 1. Bleeding time

\begin{tabular}{|c|c|c|c|c|}
\hline No & Group & Mice & Bleeding time & Mean (SD) \\
\hline \multirow{5}{*}{1} & \multirow{5}{*}{ Control (-) (distilled water) } & 1 & 210 & \multirow{5}{*}{$246.00(22.95)$} \\
\hline & & 2 & 240 & \\
\hline & & 3 & 267 & \\
\hline & & 4 & 264 & \\
\hline & & 5 & 249 & \\
\hline \multirow{5}{*}{2} & \multirow{5}{*}{ Control (+) (epinephrin) } & 1 & 64 & \multirow{5}{*}{$72.40(5.55)$} \\
\hline & & 2 & 70 & \\
\hline & & 3 & 74 & \\
\hline & & 4 & 76 & \\
\hline & & 5 & 78 & \\
\hline \multirow{5}{*}{3} & \multirow{5}{*}{ P. guajava leaves } & 1 & 84 & \multirow{5}{*}{$88.40(7.40)$} \\
\hline & & 2 & 80 & \\
\hline & & 3 & 86 & \\
\hline & & 4 & 94 & \\
\hline & & 5 & 98 & \\
\hline
\end{tabular}


time.

This result showed that the distribution of bleeding time for all three groups was normal. Data on bleeding time between groups were tested for homogeneity. Levene test value was 3.607 and the probability value was 0.059 . This showed that data variance was homogenous.

Comparability analysis showed that the bleeding time of negative control group differed significantly with that of positive control group and treatment group $(P$. guajava) $(\mathrm{P}<0.05)$. Besides, we also found out that the bleeding time of positive control group was significantly different with that of negative control group, $(\mathrm{P}<0.05)$ but not significantly different with $P$. guajava leaves group $(\mathrm{P}>0.05)$, showing that $P$. guajava leaves had comparable local hemostatic activity with positive control.

Epinephrine has vasoconstrictive effect that can decrease the capillary size. $P$. guajava contains tannin which work as a vasoconstrictor through its astringent effects. It will help the process of bleeding by reducing capillary secretion and permeability and forming a protective layer produce local vasoconstriction capillaries. ${ }^{6-11}$

\section{Conclusion}

P. guajava showed promising local hemostatic activity and can be further developed as potential hemostatic agents.

\section{Acknowledgement}

None.

\section{Funding}

None.

\section{Conflict of Interest}

None declared

\section{References}

1. Hoogenboom BJ, Smith D. Management of Bleeding and Open Wounds in Athletes. International Journal of Sports Physical Therapy. 2012;7(3):350-355.

2. Aryal KR, Wiseman D, Siriwardena AK, Bolton-Maggs PH, Hay CR, Hill J. General Surgery in patients with a bleeding diathesis: how we do it. World Journal of Surgery. 2011;35(12):260310.

3. Ohkura N, Yokouchi H, Mimura M, Nakamura R, Atsumi G. Screening for hemostatic activities of popular Chinese medicinal herbs in vitro. Journal of Intercultural Ethnopharmacology. 2015;4(1):19-23

4. Ohkura N, Tauchi C, NakayamaA, Atsumi G. Pollen typhae is a rapid hemostyptic. Blood Coagulation and Fibrinolysis. 2012;23:254-5.

5. Grabowski EF, Yam K, Gerace M. Evaluation of hemostasis in flowing blood. American Journal of Hematology. 2012;87(S1):51-55.

6. Broos K, Feys HB, De Meyer SF, Vanhoorelbeke K, Deckmyn H. Platelets at work in primary hemostasis. Blood Review. 2011;25:155-167.

7. De-Witt SM. Identification of platelet function defects by multi-parameter assessment of thrombus formation. Nature Communications. 2014;5:42-57.

8. Monroe DM, Hoffman M. The clotting system - a major player in wound healing. Haemophilia. 2012. July;18 Suppl 5:11-6

9. Yunoki K, Naruko T, Sugioka K, Inaba $\mathrm{M}$, Itoh A, Haze $\mathrm{K}$, et al. Thrombus aspiration therapy and coronary thrombus components in patients with acute STelevation myocardial infarction. Journal of Atherosclerosis and Thrombosis. 2013;20(6):524-37.

10. Panovski MJ, Fildishevski IV, Ognjenovic LL, Dejanova-Ilijevska VI. New surgical 
technologies could facilitate surgical hemostasis in hemophilic patients. Macedonian Journal of Medical Sciences. 2017;5(3):295-298.

11. Sogut O. Erdogan MO, Kose R, Boleken ME. Hemostatic efficacy of a traditional medicine plant extract (Ankaferd Blood Stopper) in bleeding control. Clinical and Applied Thrombosis / Hemostasis. 2015;21(4):438-351. 